\title{
O PRINCÍPIO FUNDAMENTAL DA DIGNIDADE DA PESSOA HUMANA E O DIREITO À VIDA: A EVENTUAL COLISÃO DESSES PRINCÍPIOS FUNDAMENTAIS NA PERSPECTIVA DO ABORTO
}

\section{THE FUNDAMENTAL PRINCIPLE OF HUMAN DIGNITY AND THE RIGHT TO LIFE : COLLISION ANY OF THESE FUNDAMENTAL PRINCIPLES THE PERSPECTIVE OF ABORTION}

\author{
Érika do Amaral Véras ${ }^{1}$
}

\section{RESUMO}

Este artigo jurídico trabalha a temática da colisão dos princípios fundamentais, especialmente o princípio da dignidade humana e o direito à vida, na perspectiva do aborto. Primeiramente, discute-se sobre os direitos fundamentais, trazendo sua definição, observada a distinção entre os direitos humanos e fundamentais. Em seguida, o superprincípio da dignidade humana é abordado e, logo após, o direito à vida é destacado, através dos seus elementos relevantes. Por fim, discorre-se sobre a eventual colisão entre o direito fundamental à vida e o princípio da dignidade da pessoa humana, dando um enfoque especial na temática do aborto.

Palavras-Chave: Princípio da Dignidade Humana; Direito à Vida; Colisão; Proporcionalidade; Aborto.

\begin{abstract}
This legal article works the theme of the collision of the fundamental principles, especially the principle of human dignity and the right to life, abortion perspective. First, we discuss of fundamental rights, bringing its definition, observed the distinction between human rights and fundamental rights. Then the super principle of human dignity is covered and, soon after, the right to life is highlighted through its relevant elements. Finally, talks on a possible collision beween the fundamental right to life and the principle of human dignity, with a special focus on the issue of abortion.
\end{abstract}

Keywords: Principle of Human Dignity; Right to life; Collision; Proportionality; Abortion.

\footnotetext{
${ }^{1}$ Mestranda em Direito e Desenvolvimento Sustentável pelo UNIPÊ, especialista em Ordem jurídica, Ministério Público e Cidadania pela FESMIP, advogada e empregada pública. E-mail: erikaaveras@gmail.com.
} 


\section{INTRODUÇÃO}

As duas grandes guerras mundiais ${ }^{2}$, especialmente a última, e os governos totalitários que comandaram vários países causaram inúmeras mortes e consequências desastrosas para toda população mundial. Foi a partir deste momento que a humanidade passou a buscar os mecanismos que pudessem frear ou impedir que tais momentos de terror e tragédia não voltassem a ocorrer.

Dessa forma, houve o aumento da preocupação do homem por sua própria proteção, onde a luta em busca dessa proteção resultou na criação de direitos fundamentais, em especial o direito à dignidade da pessoa humana e o direito à vida. Esses dois institutos são de extrema impotância para todos os indivíduos, vez que são pressupostos de outros direitos.

Para alcançar este objetivo, a sociedade se uniu e lutou para conseguir a promulgação de leis e outros dispositivos legais que protegessem a humanidade, bem como a mudança do regime de governo, que fossem opostos aos regimes totalitários. Assim, vários países passaram a adotar o regime do estado democrático de direito, protegendo ao máximo a dignidade humana e o direito à vida.

Apesar de serem direitos muito afins e estarem intrinsecamente relacionados, fazendo parte do rol dos direitos e garantias fundamentais previstas na nossa Constituição Federal, isso não implica dizer que eles sempre estão em consonância, vez que tais direitos podem vir a se colidir.

A colisão entre o direito à vida e o princípio da dignidade da pessoa humana pode ocorrer quando existir um conflito entre viver com dignidade e morrer com dignidade, a exemplo da temática do aborto. No aborto entra-se em conflito a dignidade da gestante e o direito à vida intrauterina.

Este estudo objetiva, portanto, conceder ao leitor uma visão geral, não somente dos princípios fundamentais da dignidade da pessoa humana e o direito à vida, mas também revela a extrema importância de superar o conflito entre esses princípios, através da ponderação, quando se deparar em casos que envolvam a temática do aborto.

Partindo desse contexto é que o presente estudo procurará delinear, num primeiro momento, desde o surgimento e definição dos princípios fundamentais, destacando o

\footnotetext{
${ }^{2}$ A Primeira Guerra Mundial, conhecida também como Grande Guerra, começou em 1914 e durou até 1918. Já a Segunda Guerra Mundial começou em 1939 e durou até 1945, onde este importante e triste conflitou terminou tragicamente com as bombas atômicas em Hiroshima e Nagazaki. Tais conflitos resultaram em milhões de mortos e feridos, cidades destruídas, indústrias e zonas rurais arrasadas e dívidas incalculáveis.
} 
princípio da dignidade da pessoa humana e o direito à vida. Em seguida, contextualizará o eventual conflito entre esses dois direitos fundamentais, dando um enfoque especial na temática do aborto.

Para tanto, o método de abordagem escolhido para a elaboração do presente artigo foi o método indutivo, discorrendo sobre a eventual colisão entre os princípios fundamentais da dignidade da pessoa humana e o direito à vida na questão do aborto. Para o método de procedimento foi selecionado o método histórico que proporcionou melhor entendimento sobre as transformações sofridas pela sociedade em busca da proteção à vida e de sua dignidade, através da ponderação. E, por fim, a técnica de pesquisa aplicada para coleta de dados foi basicamente a bibliográfica.

\section{AS PARTICULARIDADES DOS DIREITOS FUNDAMENTAIS DA DIGNIDADE DA PESSOA HUMANA E DO DIREITO À VIDA}

Neste momento, iremos discorrer sobre os direitos fundamentais, através de sua definição, explicando, antes de tudo, a sua diferença com os direitos humanos, uma vez que são usualmente confundidos. Em seguida, será destacado o princípio da diginidade da pessoa humana, desde sua origem e suas significações, bem como o direito à vida. Nesse contexto, podemos perceber a extrema importância desses dois direitos à toda sociedade.

\subsection{Definindo os Direitos Fundamentais}

É importante saber o real significado da expressão "direitos fundamentais", porém, para realmente compreender esse instituto, devemos fazer uma breve observação. Durante os estudos encontramos o termo "direitos humanos" sendo utilizado como sinônimo de "direitos fundamentais". Embora essas terminologias pareçam, à princípio, semelhantes, há entendimento de que são distintas.

Para diferenciar esses dois institutos, trazemos os dizeres de Sarlet (2006, p. 35 e 36):

Direitos fundamentais referem-se àqueles direitos do ser humano que são reconhecidos e positivados na esfera do direto constitucional positivo de um determinado estado (caráter nacional). Diferem dos direitos humanos - com os quais são frequentemente confundidos - na medida em que os direitos humanos aspiram à validade universal, ou seja, são inerentes a todo ser humano como tal e a todos os povos em todos os tempos, sendo reconhecidos pelo direito internacional por meio de tratados e tendo, portanto, validade independentemente de sua positivação em uma determinada ordem constitucional (caráter supranacional). 
Neste mesmo sentido estabelece Galuppo (2003, p. 233): “[...] os Direitos Fundamentais representam a constitucionalização daqueles Direitos Humanos que gozaram de alto grau de justificação ao longo da história dos discursos morais, que são, por isso, reconhecidos como condições para a construção e o exercício dos demais direitos.”

Assim, os direitos fundamentais são aqueles reconhecidos e garantidos pela Constituição de um determinado Estado, ou seja, eles somente existem por força do texto constitucional $^{3}$ e também possuem a dignidade da pessoa humana como centro e fundamento básico.

Todos os direitos fundamentais são imperiosos para o bem-estar e a dignidade humana. Para facilitar a compreensão, vejamos a definição de Andrade (2001, p. 13):

Aquilo a que se chama ou a que é lícito chamar direitos fundamentais pode, afinal,
ser considerado por diversas perspectivas. De facto, os direitos fundamentais tanto
podem ser vistos enquanto direitos de todos os homens, independentemente dos
tempos e dos lugares - perspectiva filosófica ou jusnaturalista; como podem ser
referidos aos direitos dos homens (cidadãos), num determinado tempo e lugar, isto é,
num Estado concreto ou numa comunidade de Estados - perspectiva estadual ou
constitucional; como ainda podem ser considerados direitos de todos os homens (ou
categorias de homens) num certo tempo, em todos os lugares ou, pelo menos, em
grandes regiões do mundo - perspectiva universalista ou internacionalista.

Com base nisso, poderíamos definir os direitos fundamentais como os direitos considerados básicos para qualquer ser humano, independentemente de condições pessoais específicas.

Segundo Bonavides (2007, p. 515):

Com relação aos direitos fundamentais, Carl Schmitt estabeleceu dois critérios formais de caracterização: Pelo primeiro, podem ser designados por direitos fundamentais todos os direitos ou garantias nomeados e especificados no instrumento constitucional. Pelo segundo, tão formal quanto o primeiro, os direitos fundamentais são aqueles direitos que receberam da Constituição uma grau mais elevado de garantia ou de segurança [...]

Para Canotilho (1993, p. 541):

A função de direitos de defesa dos cidadãos sob uma dupla perspectiva:

1) constituem, num plano jurídico-objetivo, normas de competência negativa para os poderes públicos, proibindo fundamentalmente as ingerências destes na esfera jurídica individual;

2) implicam, num plano jurídico subjetivo, o poder de exercer positivamente direitos fundamentais (liberdade positiva) e de exigir omissões dos poderes públicos, de forma a evitar agressões lesivas por parte dos mesmos (liberdade negativa).

Fundamentando-se em todas essas definições trazidas à baila, podemos identificar como direitos fundamentais todos os direitos que possuem destaque dentro do texto

\footnotetext{
${ }^{3}$ Para Pérez Luño (1998, p. 47) "se trata siempre, por tanto, de derechos delimitados espacial y temporalmente, cuya denominación responde a su caráter básico o fundamentador del sistema jurídico político del Estado de Derecho".
} 
constitucional, estabelencendo e assegurando uma proteção aos direitos considerados mínimos e inerente à qualquer ser humano, afastando a atuação do Poder Público na esfera individual.

Dessa forma, os direitos fundamentais são essenciais para a existência do homem de forma digna e concretizam os valores máximos do ordenamento jurídico, na forma propugnada pelo texto constitucional, devendo subordinar toda a sociedade, incluindo o Poder Público (Estado) e os particulares que dela fazem parte. No nosso país, esses direitos estão previstos no Título II da Constituição Federal de 1988 e são revestidos da proteção ${ }^{4}$ do artigo $60, \S 4^{\circ}$ do mesmo diploma legal.

\subsection{O Princípio da Dignidade da Pessoa Humana}

Dentre os direitos fundamentais que alicerçam o Estado Democrático de Direito, está o princípio da dignidade da pessoa humana. A constitucionalização deste importante princípio em vários países do mundo, foi fruto das consequências desastrosas e devastadoras da Segunda Guerra Mundial.

Para Rocha (2004, p. 22):

Os desastres humanos das guerras, especialmente aquilo que assistiu o mundo no período da Segunda Guerra Mundial, trouxe, primeiro, a dignidade da pessoa humana para o mundo do direito como contingência que marcava a essência do próprio sociopolítico a ser traduzido no sistema jurídico.

Este marco histórico proporcionou enfatizar a dignidade humana como valor supremo, base de todo o ordenamento jurídico, um fundamento tanto político, como social, econômico e cultural.

\subsubsection{Dignidade da Pessoa Humana: A Origem do Superprincípio}

$\mathrm{Na}$ antiguidade, a dignidade da pessoa humana representava apenas os atributos externos dos indivíduos, em especial a sua posição social. Nesta época, afirmavam a existência de pessoas mais ou menos dignas, isto dependeria apenas da posição social a qual estaria inserido. Os gregos pregavam a superioridade da polis em relação ao indivíduo, já os sofistas pregavam pelo antropocentrismo, onde o homem passou a ser o elemento principal.

\footnotetext{
${ }^{4}$ Cláusulas pétreas, ou seja, trata-se de dispositivo constitucional imutável, que não poderá ser objeto de deliberação de proposta de emenda.
} 
O período medieval foi marcado pelo movimento estóico que se consolidou como iniciativa da dignidade da pessoa humana e sua singularidade. Este mesmo movimento também foi definitivo para a construção do humanismo, onde o humano passa a ser o elemento central, fundamentando-se na ética.

A evolução na concepção da dignidade alcançada no estoicismo foi não considerar a posição social ocupada pelo indivíduo, passando a determinar a dignidade como fator inerente ao ser humano, distinguindo-se, assim, das demais criaturas. Isso só foi possível quando passou a reconhecer todos os homens, indistintamente, como filhos de Zeus.

O cristianismo recepcionou o conceito formulado pelos estóicos, afastando-se apenas na medida em que fez a separação entre as esferas humana e divina, onde Deus era o único ser supremo. Assim, construiu uma concepção de dignidade humana baseada na valorização do homem como figura semelhante ao divino, tendo como principais teólogos Santo Agostinho e São Tomás de Aquino. Santo Agostinho pregava pelo livre arbítrio e São Tomás de Aquino foi o primeiro a utilizar o termo dignitas humana ${ }^{5}$ e serviu de base para o pensamento de Kant, o qual veremos adiante.

Na modernidade o antropocentrismo passou a construir a ideia de dignidade humana contemporânea, surgindo o homem na sua singularidade. O humanismo construiu uma nova concepção de homem, sendo considerado o centro do universo, dotado de valor e liberdade, onde a dignidade da pessoa humana passa a associar-se com a liberdade.

A concepção moderna da dignidade e de direitos humanos tem seu ápice com o pensamento de Kant, que ressaltou a característica do homem em um ser racional, dotado de inteligência e vontade. Para ele, o homem deve ser considerado como um fim em si mesmo em todas as suas ações, dissociado do divino e posto acima de todas as coisas, inclusive do próprio Estado.

Dessa forma, foi Kant o responsável pela consolidação das bases teóricas da noção da Dignidade Humana, onde as suas ideias foram essenciais para a atribuição do significado jurídico ao termo, bem como a determinação do sentido do seu alcance enquanto princípio positivado nos textos constitucionais.

\subsubsection{A Dignidade da Pessoa Humana e seus Significados}

\footnotetext{
${ }^{5}$ De Plácido e Silva (1967, p. 526) consigna que: “dignidade é a palavra derivada do latim dignitas (virtude, honra, consideração), em regra se estende a qualidade moral, que, possuída por uma pessoa serve de base ao próprio respeito em que é tida".
} 
Após as atrocidades da Segunda Guerra Mundial, a humanidade passou a buscar cada vez mais a sua proteção, visando garantir aos indivíduos uma vida digna. Através de muito esforço e luta, elaboraram documentos que foram essenciais à fundamentação deste importante princípio.

A dignidade da pessoa humana passou a ser o centro e o fundamento básico de todo preceito constitucional relativos à direitos fundamentais. Isto acontece porque todo direito fundamental previsto na Constituição possui em si o princípio da dignidade da pessoa humana.

Diversos autores buscaram definir este princípio, porém essa é uma tarefa nada fácil. Canotilho (1993, p. 367) afirma que "a literatura recente tem evitado formular um conceito sobre princípio da dignidade da pessoa humana para não incorrer num conceito 'fixista' e filosoficamente sobrecarregado."

Isto acontece em razão da necessidade deste príncipio se adequar ao surgimento de novas necessidades do ser humano, uma vez que estas se modificam de acordo com a evolução das sociedades.

Para melhor compreensão, vejamos a definição de Ingo Sarlet (2011, p. 73):

Temos por dignidade da pessoa humana a qualidade intrínseca e distintiva reconhecida em cada ser humano que o faz merecedor do mesmo respeito e consideração por parte do Estado e da comunidade, implicando, neste sentido, um complexo de direitos e deveres fundamentais que assegurem a pessoa tanto contra todo e qualquer ato de cunho degradante e desumano, como venham a lhe garantir as condições existenciais mínimas para uma vida saudável, além de propiciar e promover sua participação ativa e co-responsável nos destinos da própria existência e da vida em comunhão com os demais seres humanos mediante o devido respeito aos demais seres que integram a rede da vida.

Vejamos também as lições de Moraes (2006, p. 115-116):

No mundo social existem duas categorias de valores: o preço (preis) e a dignidade (Würden). Enquanto o preço representa um valor exterior (de mercado) e manifesta interesses particulares, a dignidade representa um valor interior (moral) e é de interesse geral. As coisas tem preço; as pessoas, dignidade. $\mathrm{O}$ valor moral se encontra infinitamente acima do valor de mercadoria, porque, ao contrário deste, não admite ser substituído por equivalente. Daí a exigência de jamais transformar o homem em meio para alcaçar quaisquer fins. Em consequência, a legilação elaborada pela razão prática, a vigorar no mundo social, deve levar em conta, como sua finalidade máxima, a realização de valor intrínseco da dignidade humana.

Este é um princípio orientador de todo o ordenamento jurídico, onde as normas já tem em seu espírito o respeito ao princípio da dignidade da pessoa humana. A referida dignidade, quando princípio fundamental, constitui-se em valor-guia de toda a ordem jurídica, sendo indispensável para a ordem social. 
É neste sentido que a Constituição Federal de 1988, mais conhecida como "Constituição Cidadã", inaugurou um novo ciclo centrado na dignidade da pessoa humana, onde esta foi a primeira Carta Magna brasileira a trazer expressamente o referido princípio. Este princípio encontra-se disciplinado no artigo $1^{\circ}$, III da CF/88. Vejamos:

Art. $1^{\circ}$ A República Federativa do Brasil, formada pela união indissolúvel dos Estados e Municípios e do Distrito Federal, constitui-se em Estado Democrático de Direito e tem como fundamentos:

(...)

III - a dignidade da pessoa humana;

Para Sartlet (2011, p. 65):

Consagrando expressamente, no título dos princípios fundamentais, a dignidade da pessoa humana como um dos fundamentos do nosso Estado democrático (e social) de Direito (art. $1^{\circ}$, inc. III, da CF), nosso constituinte de 1988 - a exemplo do que ocorreu, entre outros países, na Alemanha -, além de ter tomado uma decisão fundamental a respeito do sentido, da finalidade e da justificação do poder estatal e do próprio Estado, reconheceu categoricamente que é o Estado que existe em função da pessoa humana, e não o contrário, já que o ser humano constitui a finalidade precípua, e não meio da atividade estatal.

Tal princípio não implica somente em um dever negativo por parte do Estado, mas também em um dever positivo no sentido de garantir aos cidadãos uma existência efetivamente digna, provendo suas necessidades mais elementares. Da mesma forma, deve ser aplicado na esfera das relações entre particulares, existindo os deveres de proteção e respeito.

Este pensamento é ratificado pelas palavras de Alexandre de Moraes (2003, p. 50/51):

O princípio fundamental consagrado pela Constituição Federal da dignidade da pessoa humana apresenta-se em uma dupla concepção. Primeiramente, prevê um direito individual protetivo, seja em relação ao próprio estado, seja em relação ao demais indivíduos. Em segundo lugar, estabelece verdadeiro dever fundamental de tratamento igualitário dos próprios semelhantes. Esse dever configura-se pela exigência do indivíduo respeitar a dignidade de seu semelhante tal qual a Constituição Federal exige que lhe respeitem a própria.

A dignidade da pessoa humana se impõe na nova ordem constitucional como limite e tarefa do Estado, bem como deve servir como norte para todos os atos dos indivíduos. Além do mais, é o principal critério que ampara a existência dos direitos fundamentais.

O referido superprincípio, conforme o disposto no texto constitucional, é um dos fundamentos basilares da República Federativa do Brasil. A posição de destaque dada aos princípios fundamentais, em especial a dignidade da pessoa humana, deixa transparecer a nítida intenção do legislador em outorgar a qualidade de normas embasadoras, integrantes do núcleo essencial da nossa Constituição. 


\subsection{O Direito à Vida}

O direito à vida também é definido como direito e garantia fundamental e não pode ser relacionado apenas às questões fisiológicas. A defesa deste direito possui um caráter bastante relevante à maioria dos países que o consideram como um direito inviolável, a exemplo do Brasil.

Tal direito está disciplinado em nossa Constituição Federal, mais precisamente em seu artigo $5^{\circ}$, vejamos:

Art. $5^{\circ}$ Todos são iguais perante a lei, sem distinção de qualquer natureza, garantindo-se aos brasileiros e aos estrangeiros residentes no País a inviolabilidade do direito à vida, à liberdade, à igualdade, à segurança e à propriedade, nos termos seguintes: (grifo nosso)

Para Silva (2003, p. 196):

Vida no texto constitucional (art. $5^{\circ}$, caput), não será considerada apenas no seu sentido biológico de incessante auto-atividade funcional, peculiar à matéria orgânica, mas na sua acepção biográfica mais compreensiva. [...] É um processo que se instaura com a concepção [...], tranforma-se, progride, mantendo sua identidade, até que muda de qualidade, deixando, então, de ser vida para ser morte. Tudo que interfere em prejuízo deste fluir espontâneo e incessante contraria a vida.

Neste tópico, os elementos relevantes sobre o direito fundamental à vida serão abordados, mostrando sua importância ao conjunto dos direitos fundamentais e discutindo as afirmações de que este direito é um direito absoluto, no sentindo de não admitir qualquer interferência ou mitigação.

\subsubsection{A Constitucionalização do Direito à Vida No Brasil}

Igualmente ao princípio da dignidade da pessoa humana, o direito fundamental à vida passou a ganhar destaque após os desastres da Segunda Guerra Mundial, momento em que este direito passou a ser notadamente expresso e ganhou fortalecimento após os terríveis acontecimentos do século XX, como o holocauto, os governos totalitários e ditatoriais. Um dos principais fatores ao destaque desse direito, que transformou-se num direito constitucional, se deu muito em função da permissão da pena de morte no período pós-guerra.

No nosso país, as Constituições de 1824 e de 1891 não enunciaram expressamente o direito à vida, porém, vale destacar que a última aboliu de seu texto constitucional a previsão da pena de morte em tempos de paz. As disposições deste último diploma legal foram reproduzidas na Constituição de 1934. Deferentemente da Carta Magna de 1937, que além de 
não prever em seu texto o direito à vida, aumentou as hipóteses de instituição da pena de morte em tempos de $\mathrm{paz}^{6}$.

Em contrapartida, após o período da Segunda Guerra Mundial, a Constituição de 1946 foi a primeira a positivar o direito à vida de forma expressa no caput do artigo $141^{7}$, onde esse mesmo texto passou a ser reproduzido na Lei Maior de $1967^{8} \mathrm{e}$, hoje, assemelha-se ao caput do artigo $5^{\circ 9}$ da Constituição Federal de 1988, constituição vigente.

Assim, o direito à vida passou a assumir uma relevância ímpar nas sociedades. Para Bulos (2009, p. 442) "O direito à vida é o mais importante dos direitos”. A nossa legislação, ao meu ver, comete apenas um deslise ao não pontuar o momento em que começa ou termina a vida ${ }^{10}$, mesmo contendo vários dispositivos que consegram e protegem o direito à vida.

\subsubsection{O Direito à Vida como um Direito Absoluto}

\footnotetext{
6“'Art 122 - A Constituição assegura aos brasileiros e estrangeiros residentes no País o direito à liberdade, à segurança individual e à propriedade, nos termos seguintes: [...] 13) não haverá penas corpóreas perpétuas. As penas estabelecidas ou agravadas na lei nova não se aplicam aos fatos anteriores. Além dos casos previstos na legislação militar para o tempo de guerra, a lei poderá prescrever a pena de morte para os seguintes crimes:

a) tentar submeter o território da Nação ou parte dele à soberania de Estado estrangeiro;

b) tentar, com auxilio ou subsidio de Estado estrangeiro ou organização de caráter internacional, contra a unidade da Nação, procurando desmembrar o território sujeito à sua soberania;

c) tentar por meio de movimento armado o desmembramento do território nacional, desde que para reprimi-lo se torne necessário proceder a operações de guerra;

d) tentar, com auxilio ou subsidio de Estado estrangeiro ou organização de caráter internacional, a mudança da ordem política ou social estabelecida na Constituição;

e) tentar subverter por meios violentos a ordem política e social, com o fim de apoderar-se do Estado para o estabelecimento da ditadura de uma classe social;

f) o homicídio cometido por motivo fútil e com extremos de perversidade;"

7 "Art. 141 - A Constituição assegura aos brasileiros e aos estrangeiros residentes no País a inviolabilidade dos direitos concernentes à vida, à liberdade, a segurança individual e à propriedade, nos termos seguintes:"

8 "Art 150 - A Constituição assegura aos brasileiros e aos estrangeiros residentes no Pais a inviolabilidade dos direitos concernentes à vida, à liberdade, à segurança e à propriedade, nos termos seguintes:"

9 “Art. $5^{\circ}$ Todos são iguais perante a lei, sem distinção de qualquer natureza, garantindo-se aos brasileiros e aos estrangeiros residentes no País a inviolabilidade do direito à vida, à liberdade, à igualdade, à segurança e à propriedade, nos termos seguintes:"

${ }^{10}$ Segundo Gonçalves (2009, p. 455): "Acerca do início da vida, podem ser listadas cinco respostas básicas da ciência, a saber: a visão genética (que teoriza que a vida humana começa na fertilização, opinião que hoje é atacada pela Igreja Católica); a visão embrionária (segundo a qual a vida humana tem início na terceira semana de gestação); a visão neurológica (a vida só teria início com a atividade elétrica do cérebro, sendo certo que não há consenso temporal, eis que alguns estudiosos já afirmam existir tais sinais na $8^{\mathrm{a}}$ semana de gestação, enquanto outros só encontram na $20^{\mathrm{a}}$ semana. A razão central desta teoria decorre do fato da necessidade de uniformização de critérios com relação ao momento terminal da vida, cuja corrente majoritária afirma ser a morte cerebral); a visão ecológica (que leva em consideração a $24^{a}$ semana, sendo induvidoso que este foi o critério seguido pela Corte Constitucional norte-americana, no julgamento permissivo do aborto naquele país) e a visão metabólica (segundo a qual a questão do início da vida é irrelevante). No que tange ao término da vida, a maioria dos estudioso advoga a tese de que a existência de atividade cerebral é que determina a presença de qualquer sopro de vida nos seres humanos."
} 
Apesar de se encontrar numa posição de destaque no nosso ordenamento jurídico, o direito à vida não pode ser reconhecido como um direito absoluto ${ }^{11}$. Segundo Junges (1995, p. 117) "a possibilidade de a vida nunca entrasse em conflito com outros bens e valores e superasse sempre em valor todo bem ou conjunto de bens que conflitasse com ela. Ora, isto não acontece. Ocorre antes o contrário.” Dessa forma, o direito à vida não poderá prevalecer sobre qualquer outro direito, afastando essa característica de absoluto.

Neste mesmo sentido, afirmam Mendes, Coelho e Branco (2008, p. 240):

Tornou-se voz corrente na nossa família do Direito admitir que os direitos fundamentais podem ser objeto de limitações, quando enfrentam outros valores de ordem constitucional, inclusive outros direitos fundamentais. Prieto Sanchis noticia que a afirmação 'não existem direitos ilimitados' se converteu quase em uma cláusula de estilo na jurisprudência de todos os tribunais competentes em matéria de direitos humanos.

O nosso texto constitucional, por si só, mitiga o referido direito ao prever a pena de morte, conforme os artigos $5^{\circ}$, XLVII, alínea a, e 84, XIX da Carta Magna. Também devemos destacar o Código Penal Militar que, igualmente, mitiga o direito à vida ao prever a pena de morte, nos casos estabelecidos no artigo 355 e seguintes.

No que se refere às leis infraconstitucionais, devemos atentar ao nosso Código Penal, uma vez que o mesmo permite a interrupção da vida (intra-uterina), de forma extraordinária, no momento em que disciplina sobre o aborto, mais especificadamente no artigo $128^{12}$. Onde, tal dispositivo, atualmente, é complementado pela Arguição de Descumprimento de Preceito Fundamental - ADPF n ${ }^{\circ} 54^{13}$.

O direito à vida tem grande importância e destaque entre os direitos fundamentais, sendo pressuposto de outros direitos, mas que não pode ser considerado absoluto. Assim, analisando cada caso, o direito à vida poderia ser restringido ou limitado, demonstrando a possibilidade de mitigação dessa proteção quando se tem outros direitos fundamentais

\footnotetext{
${ }^{11}$ Vale salientar que este é um assunto no qual não encontramos um consenso, há doutrinadores, a exemplo de Maria Helena Diniz, que afirmam que o mesmo é absoluto.

12 “Art. 128 - Não se pune o aborto praticado por médico: I - se não há outro meio de salvar a vida da gestante; II - se a gravidez resulta de estupro e o aborto é precedido de consentimento da gestante ou, quando incapaz, de seu representante legal."

${ }^{13}$ A ADPF 54 prevê a possibilidade de aborto de feto anencéfalo, afastando a tipificação dos artigos 124 e 126 do nosso Código Penal. ADPF 54 - Ementa: "ESTADO - LAICIDADE. O Brasil é uma república laica, surgindo absolutamente neutro quanto às religiões. Considerações. FETO ANENCÉFALO - INTERRUPÇÃO DA GRAVIDEZ - MULHER - LIBERDADE SEXUAL E REPRODUTIVA - SAÚDE - DIGNIDADE AUTODETERMINAÇÃO - DIREITOS FUNDAMENTAIS - CRIME - INEXISTÊNCIA. Mostra-se inconstitucional interpretação de a interrupção da gravidez de feto anencéfalo ser conduta tipificada nos artigos 124, 126 e 128, incisos I e II, do Código Penal.

(STF - ADPF: 54 DF, Relator: Min. MARCO AURÉLIO, Data de Julgamento: 12/04/2012, Tribunal Pleno, Data de Publicação: ACÓRDÃO ELETRÔNICO DJe-080 DIVULG 29-04-2013 PUBLIC 30-04-2013)"
} 
envolvidos. Ou seja, o direito à vida deve ter primazia sobre os demais, podendo, excepcionalmente, ser afastado de forma razoável e proporcional em vista das circunstâncias fáticas.

Desta forma, fica nítido que nossa legislação prevê possibilidades de mitigação desse importante direito fundamental, seja com o instituto da pena de morte, seja com a possibilidade da prática do aborto (veremos mais adiante), que, consequentemente, não deve ser considerado como direito absoluto.

\title{
3 DA COLISÃO ENTRE O PRINCÍPIO FUNDAMENTAL DA DIGNIDADE HUMANA E O DIREITO À VIDA NA PERSPECTIVA DO ABORTO
}

O princípio da dignidade da pessoa humana e o direito à vida estão intrinsecamente relacionados, onde ambos institutos fazem parte do rol dos direitos e garantias fundamentais previstas na nossa Constituição Federal. No prefácio da obra de Silva (2002, p. 12), Paulo Bonavides fez o seguinte destaque: "Proteger a dignidade do homem é proteger a vida e o direito, $[\ldots] "$.

Esse pensamento ratifica a grande ligação entre esses dois direitos fundamentais. Entretanto, apesar de possuírem tamanha relação, isso não implica dizer que eles sempre estão em consonância, vez que tais direitos podem vir a colidir.

\subsection{A Eventual Colisão dos Princípios Fundamentais}

A colisão entre o direito à vida e o princípio da dignidade da pessoa humana pode ocorrer quando existir um conflito entre viver com dignidade e morrer com dignidade ${ }^{14}$.

\begin{abstract}
Alguns defendem a idéia de que a vida sem dignidade não é uma verdadeira vida, razão pela qual seria plenamente aceitável a relativização do direito à vida. A outra corrente ideológica assevera que a vida é pressuposto lógico da dignidade da pessoa humana, ou seja, não há o que cogitar da vida ser digna ou indigna se não houver vida em si. Logo, advogam a tese de que o direito à vida não pode ser apequenado. (GONÇALVES, 2009)
\end{abstract}

\footnotetext{
${ }^{14}$ Baiges (2002, p. 53-59) entende que o direito de morrer com dignidade consiste no poder recusar toda decisão alheia que leve a uma morte não desejada pelo titular desse direito. Enseja no direito a morrer com serenidade, a recusar o prolongamento do tratamento terapêutico ou qualquer outro tratamento médico, ainda que isto resulte na morte do titular. É o direito a manifestar vontades prévias de como se deseja morrer, um direito a ter um tratamento paliativo da dor no processo da morte e o direito de determinar o momento da própria morte.
} 
Diante desta diferença de pensamentos, onde por um lado o direto à vida é visto como um direito absoluto em detrimento da dignidade e por outro a dignidade da pessoa é vista como um direito absoluto em detrimento à vida, observamos que ambas teorias pecam pelo julgamento prévio, sem análise minuciosa de cada caso para ser alcançado o equilíbrio e justiça.

Para Gustavo Zagrebelsky (2003, p. 16) o direito constitucional deve ser flexível, afastando a hipóteses de direitos absolutos, não podendo prevalecer um só valor ou um só princípio, devendo resguardar vários, senão todos, direitos simultaneamente. Dessa forma, a melhor solução seria a ponderação desses direitos fundamentais constitucionais.

Assim, a ponderação busca alcançar o melhor equilíbrio entre os direitos à vida e a dignidade da pessoa humana, ora em conflito.

\subsection{Da Perspectiva do Aborto}

O aborto foi amplamente discutido em tribunais ocidentais pricipalmente após a década de 70, momento em que se deu talvez o maior caso julgado pela Suprema Corte dos Estados Unidos da América, o conhecidíssimo Roe vs. Wade.

Segundo Dworkin (2003, p. 141):

O caso Roe contra Wade é, sem dúvida, o mais famoso de todos os que já foram decididos pelo Supremo Tribunal dos Estados Unidos: é o mais conhecido pelos nortes-americanos - e, na verdade, no mundo inteiro - do que Marbury contra Madison [...], ou do que Dred Scott contra Sanford, [...], ou mesmo do que Brown contra Board of Education, [...].

Tal instituto se manteve na pauta de pesquisas brasileiras nos últimos 20 anos, onde se verificou que o alto índice de mortalidade materna no Brasil está inegavelmente vinculado à criminalização do aborto. De acordo com o Ministério da Saúde (2007, p. 33), o aborto é a quarta causa de mortes maternas no Brasil, devido a hemorragias e infecções.

Segundo o mesmo Ministério (2008, p. 8-9), as estimativas mais recentes indicam um número entre 728.100 e 1.039 .000 abortos a cada ano. Apesar do decréscimo neste número na última década, a taxa atual de 3,7 abortos por 100 mulheres em idade reprodutiva ainda representa uma das mais altas do mundo.

Faúnes (2004, p. 61-62) afirma que no Brasil, assim como em diversos países do mundo, o abortamento representa um grave problema de saúde pública, justiça social e 
direitos humanos. A criminalização do aborto reforça o estigma social e religioso a que as mulheres estão sujeitas, criando um ambiente marcado pela violência simbólica de gênero.

No contexto de clandestinidade do abortamento, as mulheres submetem-se a condições precárias e inseguras para a realização do procedimento. $\mathrm{O}$ aborto é crime ${ }^{15}$, mas não deixa de ser realizado diariamente por milhares de mulheres que resistem à opressão de gênero e estabelecem que são elas, e mais ninguém, as donas dos seus corpos. As referidas práticas dificilmente resvalam em processos criminais em razão das dificuldades, uma vez que os números de denúncias oferecidas quanto ao crime de aborto são extremamente escassos, considerando o grande número de abortos praticados.

No Brasil, a nossa legislação, excepcionalmente, permite o aborto apenas nos casos de uma gravidez de risco à vida da mãe, quando a concepção resulta de um estupro ou quando o feto é anencéfalo. Vejamos o que dispõe nosso dispositivo legal penal:

Art. 128 - Não se pune o aborto praticado por médico:

I - se não há outro meio de salvar a vida da gestante;

II - se a gravidez resulta de estupro e o aborto é precedido de consentimento da gestante ou, quando incapaz, de seu representante legal.

Dessa forma, observamos que o referido diploma assegura apenas dois tipos de aborto, uma vez que o último tipo somente encontra proteção na Arguição de Descumprimento de Preceito Fundamental - ADPF 54.

A interrupção de uma gravidez, mesmo de um feto anencéfalo, confronta diretamente o direito fundamental à vida em face de outros direitos fundamentais, especialmente o direito à dignidade da pessoa humana, à liberdade, à saúde, à autonomia individual, à autodeterminação, à integridade física e psíquica e o reconhecimento pleno de direitos individuais, especificamente, os direitos sexuais e reprodutivos das mulheres.

Aqui, é inevitável o confronto entre os interesses legítimos da mulher em ver respeitada sua dignidade e os interesses de parte da sociedade que desejam proteger todos os que a integrariam, independentemente da condição física ou viabilidade de sobrevivência.

Não obstante o STF ter legalizado a interrupção da gravidez nos casos que envolvem a anencefalia, no ano de 2012, o tema permanece um tabu no meio jurídico, médico, teológico e social. Além de polêmico, movimenta diversos setores da sociedade, levantando além das questões jurídicas, implicações morais, religiosas, éticas, ideológicas, sociológicas, dentre outras. Assim, a questão penal tornou-se um mero detalhe, não devendo afastar a discussão

${ }^{15}$ O Código Penal Brasileiro considera crime o aborto provocado, como consta dos artigos 124 a 127 deste diploma legal. 
sobre a necessidade ou não de reforma dos delitos disciplinados nos artigos 124, 125 e 126 do Código Penal Brasileiro, ou seja, dos tipos de aborto.

\section{CONSIDERAÇÕES FINAIS}

O princípio da dignidade da pessoa humana e o direito à vida são os direitos fundamentais de maior destaque no nosso ordenamento jurídico. Os dois institutos passaram a ganhar mais importância somente após a Segunda Guerra Mundial, episódio responsável pela criação de normas que visavam a proteção da humanidade contra as atrocidades ocorridas na época.

Foi a partir deste momento que a dignidade da pessoa humana e o direito á vida começaram a ser constitucionalizados, protegendo todos os indivíduos. O direito à vida começou a ser expressamente resguardado na Constituição de 1946 e a dignidade da pessoa humana somente passou a ser previsto expressamente na Constituição Cidadã de 1988.

Os direitos fudamentais assumem uma posição de supremacia, mediante as demais normas, são classificados como cláusula pétrea, não restando dúvida sobre sua prevalência sobre as demais normas na incidência de algum conflito.

Porém, a principal questão é o que fazer quando dois direitos fundamentais entram em conflito. Por possuírem a mesma natureza e característica, um não poderá prevalecer mais que outro, principalmente quando se tratem de dois direitos tão especiais como a dignidade da pessoa humana e o direito à vida.

Apesar de serem direitos muito afins e estarem intrinsecamente relacionados, fazendo parte do rol dos direitos e garantias fundamentais previstas na nossa Constituição Federal, isso não implica dizer que eles sempre estão em consonância, podendo vir a se colidir. Para melhor ilustrar tal afirmação, foi trazido ao texto a temática do aborto, onde conflitam-se a dignidade da gestante e o direito à vida intrauterina.

Podemos concluir através deste estudo, portanto, a relevância dos princípios fundamentais da dignidade da pessoa humana e o direito à vida, mas também a extrema importância de superar o conflito entre esses dois institutos, através da ponderação, quando se deparar em casos que envolvam a temática do aborto. 


\section{REFERÊNCIAS}

ANDRADE, José Carlos Vieira de. Os direitos fundamentais na Constituição Portuguesa de 1976. $2^{\text {a }}$ ed. - Coimbra: Livraria Almedina, 2001.

BAIGES, Victor Méndez. Sobre morir: eutanásias, derechos, razones. Madrid: Editorial Trotta, 2002.

BONAVIDES, Paulo. Curso de Direito Constitucional. 21 ed. São Paulo: Malheiros, 2007.

BRASIL, Constituição (1946). Constituição dos Estados Unidos do Brasil. Rio de Janeiro: Senado Federal, $1946 . \quad$ Disponível em: <http://www.planalto.gov.br/ccivil_03/Constituicao/Constituicao46.htm>. Acessado em 04 jul 16.

BRASIL, Constituição (1937). Constituição dos Estados Unidos do Brasil. Rio de Janeiro: Senado $\quad 1937 . \quad$ Federal, Disponível em: <http://www.planalto.gov.br/ccivil_03/constituicao/constituicao37.htm>. Acessado em 04 jul 16.

BRASIL, Constituição (1967). Constituição dos Estados Unidos do Brasil. Brasília: Senado $1967 . \quad$ Federal, Disponível em: <http://www.planalto.gov.br/ccivil_03/Constituicao/Constituicao67.htm>. Acessado em 04 jul 16.

BRASIL, Constituição (1988). Constituição da República Federativa do Brasil. Brasília: Senado $\quad 1988 . \quad$ Federal, $\quad$ Disponível em: <https://www.planalto.gov.br/ccivil_03/constituicao/constituicaocompilado.htm>. Acessado em 04 jul 16.

BRASIL, Código Penal Militar (1969). Decreto-Lei no 1.001, de 21de outubro de 1969. Disponível em: <https://www.planalto.gov.br/ccivil_03/decreto-lei/Del1001.htm>. Acessado em 04 jul 16.

BRASIL, Código Penal (1940). Decreto-Lei no 2.848, de 07 de dezembro de 1940. Disponível em: <https://www.planalto.gov.br/ccivil_03/decreto-lei/Del2848compilado.htm>. Acessado em 04 jul 16. 
BRASIL. Ministério da Saúde. Relatório de Gestão. Secretaria de Atenção à Saúde. Área Técnica de Saúde da Mulher. 2003-2006. Brasília, 2007.

BRASIL. Ministério da Saúde. A Magnitude do Aborto no Brasil: Aspectos Epidemiológicos e Sócio-Culturais. Abortamento Previsto em Lei em Situações de Violência Sexual. Brasília: Ministério da Saúde, 2008. p. 8-9.

BUlOS, Uadi Lammêgo. Curso de Direito Constitucional. $4^{\text {a }}$ ed. ref. atual. São Paulo: Saraiva, 2009.

CANOTILHO, José Joaquim Gomes. Direito Constitucional. Coimbra: Almedina, 1993.

DWORKIN, Ronald. Domínio da vida: aborto, eutanásia e liberdades individuais. Tradução de Jefferson Luiz Camargo. São Paulo: Martins Fontes, 2003.

FAÚNDES, Aníbal; BARZELATTO, José. O Drama do Aborto: em busca de um consenso. Campinas: Komedi, 2004.

GALUPPO, Marcelo Campos. O que são direitos fundamentais? In: SAMPAIO, José Adércio Leite. Jurisdição constitucional e direitos fundamentais. Belo Horizonte: Del Rey, 2003.

GONÇALVES, Rogério Magnus Varela. A dignidade da pessoa humana e o direito à vida. In: ALMEIDA FILHO, Agassiz e MELGARÉ, Plínio (organizadores). Dignidade da Pessoa Humana. São Paulo: Malheiros, 2009.

JUNGES, José Roque. Bioética: perspectivas e desafios. São Leopoldo: Unisinos, 1995.

MENDES, Gilmar Ferreira et al.Curso de Direito Constitucional. 2. ed. São Paulo/Brasília: Saraiva/IDP, 2008.

MORAES, Alexandre de. Direitos Humanos Fundamentais: teoria geral, comentários aos artigos 1. a 5. da Constituição Federativa do Brasil, doutrina e jurisprudência. $5^{\text {a }}$ ed. São Paulo: Atlas, 2003. 
MORAES, Maria Celina Bodin. O conceito da dignidade humana: subtrato axiológico e conteúdo normativo. In: SARLET, Ingo Wolfgang (organizador). Constituiçãa, direitos fundamentais e direito privado. $2^{\mathrm{a}}$ ed. Porto Alegre: Livraria do Advogado, 2006.

PÉREZ LUÑO, Antonio Enrique. Los derechos fundamentales. Madrid: Tecnos, 1998.

ROCHA, Carmem Lúcia Antunes. O Direito à vida digna. Belo Horizonte: Editora Fórum, 2004.

SARLET, Ingo Wolfgang. A eficácia dos direitos fundamentais. $6^{\mathrm{a}}$ ed. Porto Alegre: Livraria do Advogado, 2006.

SARLET, Ingo Wolfgang Sarlet. Dignidade da Pessoa Humana e Direitos Fundamentais na Constituiçãa Federal de 1988. 9 ed. Rev. Atual. Porto Alegre: Livraria do Advogado, 2011.

SILVA, De Plácido e. Vocabulário Jurídico. Vol. II; São Paulo: Forense, 1967.

SILVA, José Afonso da. Curso de Direito Constitucional Positivo. São Paulo: Malheiros, 2003.

SILVA, Reinaldo Pereira. Introdução ao Biodireito: investigações político-jurídicas sobre o estatuto da concepção humana. São Paulo: LTr, 2002.

ZAGREBelsKY, Gustavo. El Drecho Dúctil. Ley, Derechos, Justicia. Trad. de Marina Gascón. $5^{\text {a }}$ ed., Madrid, Trotta, 2003. 